\title{
El antisemitismo como ideología. Su expresión en Chile
}

\author{
Antisemitism as ideology. Its expression in Chile
}

\author{
Dr. Hugo Harvey \\ hugo_harvey@yahoo.com \\ Universidad de Chile \\ Chile
}

\section{Resumen}

La expresión "ideología" es un concepto voluble, que no siempre significa lo mismo para diferentes lectores. En su forma más simple, una ideología puede ser entendida como un conjunto de ideas que proporcionan las bases para una acción organizada, y en tal sentido, no tiene una connotación negativa per se. Quizás por ello mismo ha pasado desapercibida su asociación con el antisemitismo, situación en la cual la ideología sí adquiere una presencia de intolerancia hacia los valores de las comunidades judías, o al menos percibidos como asociados a las actitudes judías. Tal es el interés del presente artículo, orientado a delinear algunos alcances y puntos de encuentro entre los conceptos mencionados, buscando destacar, en forma resumida, la forma en que se expresó en Chile.

Palabras clave: Ideología - Antisemitismo - Intolerancia - Prejuicio

\begin{abstract}
"Ideology" is a fickle concept that does not always mean the same for different readers. In its simplest form, an ideology can be understood as a set of ideas that provide the basis for organized action, and in that sense, it has no negative connotation per se. Perhaps that's why it its association with anti-semitism has gone unnoticed, a situation in which it does presuppose a presence of intolerance towards the values of the Jewish communities, or at least towards those perceived associated with Jewish attitudes. Such is the interest of this article, designed to outline some extent and points of contact between the concepts mentioned, trying to underline, in summary, the way they were expressed in Chile some years ago.
\end{abstract}

Keywords: Ideology - Antisemitism - Intolerance - Prejudice 


\section{Introducción}

Es difícil encontrar en la historia algún pueblo cuya vida haya estado absolutamente desvinculada de lo religioso. En efecto, esta separación es más bien algo contemporáneo y localizado, ya que aparece en nuestros días y en mayor medida en países ubicados en occidente. Un autor ha señalado que

“(...) en las poblaciones pre cristianas el vínculo entre lo político y lo religioso era de tal índole que su disolución resultaba prácticamente impensable. Los dioses pertenecían a una colectividad determinada, y proporcionaban amparo sólo a quienes la integraban. Ser extranjero no era solamente no pertenecer a una colectividad política, sino no tener sus mismos dioses" (Widow, 1984, p.62)

No obstante, casi a la par con el surgimiento de las creencias relacionadas con la fe, emergió la intolerancia religiosa, la cual ha sido especialmente odiosa hacia una religión en particular, el judaísmo, conformando el ominoso antisemitismo. Dicho término, sin embargo, puede tener varias interpretaciones. En efecto, en primer lugar puede entenderse como el odio hacia los judíos, extendido a través de milenios y en todos los continentes. También puede ser entendido como un movimiento político relativamente moderno, que conformó una ideología, surgido en Europa en el siglo XIX y que alcanzó su apogeo con el Holocausto, o, finalmente, puede ser una versión, enfermiza e irracional, de un anti judaísmo étnico y religioso-céntrico originado en el conflicto del Cristianismo con sus raíces judías, y que llegó a su máxima expresión con el ya nombrado Holocausto. Aún más, el antisemitismo puede ser una combinación de todos los factores mencionados. Todo depende de los antecedentes que se tengan en cuenta para su definición.

Para Hannah Arendt:

"El antisemitismo, una ideología secular decimonónica - cuyo nombre, aunque no su argumentación, era desconocido hasta la década de los años setenta de ese siglo - y el odio religioso hacia los judíos, inspirado por el antagonismo recíprocamente hostil de dos credos en pugna, es evidente que no son la misma cosa; e incluso cabe poner en tela de juicio el grado en que el primero deriva sus argumentos y su atractivo emocional del segundo" (Arendt, 1973, p.6)

La destacada filósofa hace así una diferencia entre el antisemitismo, en tanto ideología, y la judeofobia, en su condición de odio religioso.

Sería el primero de estos fenómenos, surgido a fines de la Edad Media, y que se transformaría luego en el antisemitismo "moderno" del siglo XIX que menciona Arendt, el más importante porque adquiere 
dimensión política, integra la dirección de la sociedad en conjunto con el odio como instrumento y, obviamente, con la disposición de los recursos del Estado al servicio de la violencia.

\section{Objetivo}

Como señala un autor:

"Algunos conceptos, como el comunismo, si bien son complicados de explicar, son bastante simples de definir e identificar como ideología y movimiento político, y nada más que eso. El antisemitismo, por el contrario, es un término extremadamente ambivalente, multivalente incluso, que puede prestarse para una gran confusión"( Beller, 2007, pp.1-2)

El objetivo del presente ensayo, de acuerdo con lo anterior, es efectuar un estudio sobre el antisemitismo en tanto ideología, buscando establecer, de manera resumida, atendiendo a la extensión máxima permitida para el trabajo, la forma en que se manifestó en Chile.

Para lo anterior, inicialmente se hará una revisión del concepto "ideología", tras su caracterización general. A continuación se entregarán determinados conceptos relacionados con el antisemitismo, indagando sobre sus orígenes y parte de sus manifestaciones; luego se describirán algunas de sus expresiones en Chile, para finalizar entregando las conclusiones generales que se derivan de la labor realizada.

\section{Desarrollo}

\section{A. Las ideologías como concepto}

La expresión "ideología" es un concepto voluble, que no siempre significa lo mismo para diferentes lectores. Plenamente consciente de ello, Terry Eagleton concluye que:

“(...) nadie ha llegado todavía a una sola definición adecuada de ideología ... Esto no es porque los pensadores de este campo sean notables por su poca inteligencia, sino que debido a que el término "ideología" tiene una amplia gama de significados útiles, no todos compatibles con los demás"( Eagleton, 1991, p.1) 
No obstante, incluso esa aproximación, si bien incompleta, es útil para sugerir una descripción de semejante término. Cabe agregar que Eagleton más adelante señala que es posible definir la ideología en cerca de seis formas diferentes, mediante una progresiva agudización de su enfoque.

Con todo, por lo general una ideología es un sistema de creencias fundamentales animado por una serie de principios centrales sobre la naturaleza de la esfera política y social, marcado por acciones y políticas prescritas, ya sea para el mantenimiento o la reforma política. Siempre existe la tentación de ampliar la definición para incluir normas culturales y otras clasificaciones, pero hacerlo sería, en cierta forma, diluir la palabra "ideología"', mientras que implicaría, a la vez, una aproximación a lo que podría ser descrito como una "cosmovisión".

Para otro autor, la ideología se puede definir como un conjunto, más o menos coherente, esto es, mutuamente consistente, de creencias sobre el mundo, incluyendo elementos tanto empíricos como normativos. Por empírico se entiende descriptivo, que tiene que ver con cuestiones de hecho; mientras que los elementos normativos son puntos de vista sobre lo que debería ser, sobre lo que es correcto o incorrecto y sobre lo que el individuo debería hacer. Debido a que una ideología contiene estos dos tipos de elementos, relacionados entre sí de una manera coherente, como lo señala Needler, da sentido al mundo, es decir, interpreta para el individuo lo que está sucediendo; al mismo tiempo que proporciona una guía para la acción y la evaluación de lo que otros han hecho (Needler, 1996, p.33)

Por otra parte, la "Enciclopedia de Pensamiento Político", define ideología como “(...) una teoría o un conjunto de creencias sobre el mundo político que ordena nuestra percepción de los acontecimientos y explica cómo opera la sociedad". Agrega que una ideología es simplemente una visión coherente del mundo, que implica un patrón de símbolos y creencias orientados a explicar y evaluar la sociedad. Muy a menudo, la ideología se refiere simplemente a un sesgo político o de opinión. Por ejemplo, la ideología del partido Republicano en tanto ideología conservadora del libre mercado, reducción de impuestos, 
aumento del gasto militar, y así sucesivamente; o la ideología del partido Demócrata, representada por programas de bienestar social, activismo de los derechos civiles, etc. ${ }^{1}$

Finalmente, en esta revisión del significado del término, Heywood nos entrega su propio concepto de ideología, señalando que "(...) es un conjunto de ideas, más o menos coherentes, que proporcionan las bases para una acción política organizada, sin importar si ella tiene la intención de preservar, modificar o derribar el sistema de relaciones de poder existente"(Heywood, 1999, p.43)

En concreto, una ideología se diferencia de una filosofía principalmente respecto a la actitud referida a la certeza. En general, la filosofía mantiene un grado de incertidumbre debido a las limitaciones del conocimiento humano, y por lo tanto permanece abierta a un examen más detenido. Esto no implica que la filosofía niegue la posibilidad de la verdad y el conocimiento real de las cosas, sino que siempre deja abierta la posibilidad de una necesidad de reexaminar las certezas y de estar dispuesta a la aparición de nuevas vías de conocimiento.

En ese sentido, la ideología se caracteriza por un mayor grado de certidumbre con respecto a sus principios básicos y por lo tanto es menos abierta a la reconsideración de sus ideas centrales que un enfoque filosófico.

En mayor o menor grado, la ideología es un sistema cerrado de ideas, suponiendo irreflexivamente la incontrovertibilidad, en el sentido de no aceptar dudas ni disputas de sus principios esenciales y las consecuentes prescripciones de su aplicación, mientras que la filosofía, si bien siempre abierta a la posibilidad de la verdad incontrovertible ( $\mathrm{y}$ en algunos casos afirmando dichas verdades) opera desde el supuesto de que el conocimiento es limitado en relación con una certeza absoluta.

Además, una ideología es, a la vez, una expresión de aspiración política, suposición cultural e interés social, mientras que la filosofía, entendida como "amor a la sabiduría", en última instancia busca contener la suposición y superar los límites autoimpuestos como resultado del esfuerzo de un interés o deseo. 


\section{B. El antisemitismo. Una reseña}

Daniel Levinson, dice que una de las formas más claramente antidemocráticas de la ideología social es el prejuicio, y dentro de este contexto, el antisemitismo es un punto de partida fructífero para un estudio de psicología social. $^{2}$

Dos hechos, íntimamente relacionados, hacen al antisemitismo una forma única de odio. Uno de ellos es su aparente indestructibilidad. En efecto, se puede afirmar que ni siquiera la insistencia de la llustración de que la razón aplicada a todos los dogmas heredados y su llamado a la tolerancia lograron erradicarlo. El final del siglo XIX, identificado como el apogeo del liberalismo, también vio el surgimiento de movimientos antisemitas organizados y la proliferación de la difamación. En el siglo XX, el antisemitismo nazi no desanimó a los alemanes de llevar a Hitler al poder y no disminuyó su popularidad después de que privara a los judíos de sus derechos civiles.

El Holocausto silenció brevemente a los antisemitas, pero en los últimos años hemos asistido al resurgimiento del virulento odio a los judíos, en particular en el este de Europa y en algunos territorios musulmanes.

Un segundo rasgo distintivo del antisemitismo es su naturaleza irracional, es decir, el entusiasmo que lleva a las personas a creer en mitos extraordinarios acerca de los judíos. No se trata de campesinos analfabetos y de mentes incultas, por lo tanto, la pregunta que surge de manera recurrente es ¿cómo gente educada y aparentemente racional ha escrito libros con diligencia para demostrar que los judíos secuestraron y asesinaron a niños cristianos por sangre, conspiraron para dominar el planeta, y crearon una historia de exterminio con el fin de extraer dinero de Alemania? Igualmente revelador es el hecho de que los partidarios de tales fábulas persisten en sus creencias, incluso ante evidencias irrefutables, todo lo cual ilustra su profunda animadversión hacia los judíos. 
Como padre del racismo discriminatorio moderno, generalmente se reconoce al conde francés Arthur de Gobineau, autor del “Essai Sur L'Inegalite des Races Humaines” (1853). Gobineau dividió a la humanidad en tres razas básicas: blanca, amarilla y negra, y consideró la raza blanca o "aria" completamente superior, y la raza negra irremediablemente inferior. ${ }^{3} \mathrm{~A}$ pesar de esta clara categorización, las conclusiones de Gobineau eran completamente pesimistas, sosteniendo que ninguna raza podría mantener su pureza e integridad, y estaban todas condenadas a la decadencia, producto de la mezcla racial y la degeneración. Así, los judíos, a los cuales Gobineau inicialmente había considerado una de las estirpes más altas de la raza blanca, también habían caído presa de la mezcla de razas y la declinación.

No obstante, cabe mencionar que expresiones de racismo surgieron en diferentes partes del mundo y en distintas épocas, entre las cuales se pueden destacar expresiones como las siguientes:

"Los británicos somos la raza gobernante más grandiosa que el mundo haya conocido", Joseph Chamberlain (1836-1914), Ministro para las Colonias Británicas, el 11 de noviembre de 1895.

"Sostengo que somos la raza líder del mundo, y que cuanto más poblemos el mundo, mejor será este para la Humanidad. Dado que (Dios), obviamente, convirtió a la raza de habla inglesa en el instrumento elegido mediante el cual pretende construir un Estado y una sociedad basados en la justicia, la libertad y la paz, es necesario que, cumpliendo su voluntad, haga todo lo que esté en mis manos para ofrecer a esta raza tanto poder y abasto como sea posible. Pienso que en verdad existe un Dios, y es su deseo que yo haga una cosa, a saber, colorear de rojo británico el mapa de África hasta donde sea posible". Cecil Rhodes (1853 - 1902), empresario, colonizador y político británico. ( Smith, 1997, pp.556-557)

Como sea, la adopción del pensamiento racial con fines políticos pronto se extendió con mayor fuerza en la Europa central de habla alemana. Fue más allá de la simple dicotomía blanco-negro, común en el mundo de habla inglesa, para convertirse en doctrinas de "racismo místico" que creó odiosas distinciones y categorías entre los diferentes pueblos blancos de Europa, para establecer la superioridad absoluta de los arios, los nórdicos o germánicos europeos, a diferencia de los eslavos, latinos, o pueblos de los Balcanes.

El mayor divulgador del racismo místico en Alemania fue el pensador británico, nacionalizado alemán, Houston Stewart Chamberlain, cuya obra "Los fundamentos del siglo XIX" (1899), codificó las nuevas 
doctrinas germánicas de racismo místico que habían desarrollado Wagner y otros ${ }^{4}$. Más allá del estereotipo de la raza aria (alto, rubio, de ojos azules), Stewart afirmó la existencia de un "alma racial" especial, que creó un espíritu más imaginativo y profundo en los arios y produjo una "religión alemana", aunque esta última estaba vagamente relacionada con el Cristianismo.

El último enemigo racial, anti-ario y más impopular estaba representado por los judíos. Stewart combinó el darwinismo social con el racismo, enfatizando por lo tanto una lucha racial interminable en nombre de la pureza del pueblo ario y contra los judíos y pueblos inferiores, creando prácticamente un escenario propicio para una guerra entre las diferentes razas.

El racismo fue acompañado por el rápido crecimiento de nuevas doctrinas de antisemitismo, cada vez más modernas, y más raciales. La enemistad hacia los judíos en ningún momento desapareció, aunque fue bastante silenciada durante la llustración del siglo XVIII y en medio del liberalismo y el romanticismo de la primera mitad del siglo XIX. Durante las últimas cuatro décadas del siglo, sin embargo, el antisemitismo no sólo revivió, sino que se aceleró durante la década de 1890 y de allí en adelante ya no se detendría.

Por ejemplo, a fines de 1889 el director de una escuela primaria de Berlín, Hermann Ahlwardt, se enfrentaba a la perspectiva de la ruina económica. Nacido en una familia empobrecida de Pomerania en 1846, los ingresos que le proporcionaba su humilde cargo en la jerarquía educativa prusiana le resultaban insuficientes para cubrir los considerables gastos de su vida diaria. Desesperado, cometió un delito que parecía casi deliberadamente calculado para horrorizar a sus superiores: robó el dinero de los fondos recaudados para pagar la fiesta de Navidad de los niños de su escuela. No tardó en descubrirse la fechoría y fue destituido de su cargo, lo que le privó de la última fuente de ingresos que le quedaba. Estos desastres hubiesen destrozado a muchas personas, dejándolas abrumadas por sentimientos de culpa y de remordimiento, pero no a Hermann Ahlwardt. "El director de escuela", como pronto pasaría a conocérsele, decidió pasar a la ofensiva. Buscó a su alrededor a alguien a quien echarle la culpa de sus 
infortunios y no tardó en centrar su atención en los judíos, a quienes responsabilizó del delito por él cometido. ${ }^{5}$ Cabe agregar que unos años después, en 1892, luego de convencer a los campesinos de Brandenburgo de que lo eligieran para el Reichstag, había llegado al poder, lo cual le proporcionó inmunidad parlamentaria por un tiempo. Publicó numerosos escritos antijudíos, por lo que en Alemania y en Drumont (Francia) su nombre simboliza una de las peores expresiones de antisemitismo.

En concreto, el antisemitismo es una forma virulenta de intolerancia contra el pueblo judío en su conjunto, que adquiere la forma de una ideología, totalitaria e intransigente. Se puede referir a cualquier forma histórica de hostilidad hacia los judíos, incluyendo tanto a leyes y políticas antisemitas (antijudías) formalmente apoyadas por el régimen (como lo fueron, por ejemplo, las Leyes de Nuremberg de la Alemania nazi), o a obsesiones más ambiguas, pero cargadas con prejuicios sociales y culturales en contra de los judíos y el Judaísmo.

En cuanto al término "antisemitismo", su origen se remonta al periodista alemán Wilhelm Marr, quien fue el primero que lo acuñó en 1879 , al referirse a cualquier prejuicio contra los judíos y el Judaísmo, así como a la intolerancia hacia la política social y los valores culturales presentados por las comunidades judías, o al menos percibidos como asociados a las actitudes judías. Fue muy luego empleado por sectores alemanes antisemitas que, sin duda, buscaban denotar una nueva forma de antipatía hacia los judíos, planificada para ser entendida científicamente, y basada en el racismo, a diferencia de la antigua mera hostilidad religiosa.

\section{El antisemitismo en Chile}

Luego de la I Guerra Mundial, en Europa se habían dado las condiciones para la propagación de movimientos políticos de corte ultranacionalista, agrupados en su conjunto bajo el nombre genérico de fascismos. Chile no había estado ajeno a la crisis económica de 1929, que había afectado el sistema 
productivo, los ingresos y las finanzas públicas, produciéndose un enorme desempleo. Todo ello culminó con la renuncia del Presidente Ibañez en 1931. Esto produjo una problemática situación en los partidos tradicionales, y su decadencia se reflejó en una crisis general en el sistema democrático del país. Además, durante este período, el liberalismo fue objeto de severas críticas, mientras que los beneficios de la democracia liberal como sistema de gobierno fue cuestionado no sólo en Chile, sino en todo el mundo.

Por ello, el ejemplo de Europa pronto se expandió por el continente sudamericano a partir de 1930 con la aparición de una determinada cantidad de movimientos y partidos de inspiración fascista. Como señala el profesor Sergio Miranda:

"Las demandas sociales hechas por los movimientos nacionalistas hispanoamericanos coincidían básicamente con aquellas de los movimientos fascistas europeos. En todos ellos existía la misma exaltación del Estado, el culto a la tradición española (en la América española era imposible pensar en un nacionalismo que no reafirmara sus raíces españolas), el respeto por la religión común, el deseo de unidad internacional, que los protegería del rol de satélites internacionales, el principio de un líder y el anticomunismo. En todos ellos los grupos juveniles agregaron su cuota de valentía y audacia."(Miranda, 1958)

En ese orden, el libro "La Historia del Fascismo, 1914-1945", menciona que uno de los casos de interés relacionado con el fascismo fuera de Europa, es justamente el del Movimiento Nacional Socialista de Chile (MNSCH). Fundado por Jorge González von Marées en 1932, el nazismo chileno fue en parte inspirado en el nacionalsocialismo alemán, pero desarrolló sus propias características. ${ }^{6}$

En realidad, González von Marées había tratado de organizar el movimiento desde el año 1931, pero no fue sino hasta el 5 de abril de 1932 que pudo hacerlo, reunido en su estudio profesional de Agustinas 1225, junto con los demás fundadores: Carlos Keller Rueff, Juan de Dios Valenzuela, Mauricio Mena, Fernando Calvo Larrain, Luis Felipe Lazo y Gustavo Vargas Molinare. 
Durante sus años de estudio de Leyes, González von Marées había organizado una escuela vespertina para trabajadores, y había sido el presidente de la "Liga Rafael Sotomayor para la Educación Popular". Su primer desempeño laboral fue en el Juzgado de Policía Local de Ñuñoa, comuna donde fue luego secretario y más tarde, en 1932, alcalde. Sin embargo, fue despedido cuando se produjo el golpe de Marmaduque Grove, y a partir de allí, dedicó todos sus esfuerzos al MNSCH.

Bajo la tutela de su principal ideólogo, Carlos Keller, ${ }^{7}$ el $\mathrm{MNSCH}$ postulaba un nacionalsocialismo corporativista, pero económicamente radical, y una república más fuertemente centralizada y presidencialista. A la vez que organizaba tropas paramilitares nazis de asalto (TNA), propiciaba la defensa de la civilización cristiana occidental y la familia. Además, si bien definía a Chile como un país de tipo europeo, con cualidades diferentes y superiores al resto de América Latina, declaraba su oposición al imperialismo y su apoyo a los intereses internacionales de otros Estados sudamericanos. En 1937, González von Marées criticó públicamente a Hitler por haberse convertido en un tirano, y al año siguiente rechazó las relaciones o comparaciones con el nazismo o con el fascismo italiano, declarando que su movimiento era democrático.

Aunque formalmente antisemita, González von Marées admitió que no había ningún "problema judío" en Chile y teóricamente abrazó la libertad de religión. Además, von Marées rechazaba la violencia, al parecer más para obtener beneficios de ello, y sin embargo la patrocinaba como una "necesidad defensiva".

Como es sabido, un intento de golpe contra el gobierno derechista de Jorge Alessandri en septiembre de 1938 fue reprimido con facilidad, y cincuenta y cuatro nazis capturados fueron ejecutados. En 1941 el MNSCH se reconstituyó como la Vanguardia Popular Socialista, pero ya estaba en decadencia, al no encontrar un espacio político y no ofrecer una alternativa tan clara como en 1938. Además, el cambio había provocado que la gran mayoría de sus militantes abandonaran el partido producto de su izquierdización, lo que implicaba derechamente la traición a sus principios fundamentales, lo que unido al 
declive del nazismo en general, http://es.wikipedia.org/wiki/Segunda_Guerra_Mundial provocó su disolución en 1942.

Es de interés lo que menciona el Profesor Mario Sznajder respecto al MNSCH: "No sólo su interpretación histórica confiere originalidad al nazismo chileno, sino que hay tres características que distinguen claramente el MNSCH del nacionalismo del siglo XIX. Estas fueron sus actitudes con el antisemitismo, el imperialismo y el ibero-americanismo" (Sznajder, 1993, pp. 269 - 296)

El antisemitismo del $\mathrm{MNSCH}$ no era, y no podía ser, de carácter racial - biológico, debido a la naturaleza de la sociedad chilena, que era un conglomerado de distintas oleadas de inmigrantes de diversos orígenes mezclados con la población local y entre sí. Sin embargo, el nazismo chileno asimiló otros elementos del nacional-socialismo alemán, y también fue fuertemente influenciado por la visión spengleriana ${ }^{8}$ de la historia. A los ojos de la dirección del MNSCH, "el judío" personificaba el materialismo esencial presente tanto en el liberalismo como en el comunismo. A partir de este punto, era relativamente fácil relacionar los problemas de Chile con la mítica Conspiración Judía Mundial.

Por lo tanto, el MNSCH creía que la nación chilena estaba siendo atacada simultáneamente por los judíos comunistas de izquierda y por los judíos capitalistas de derecha. A los ojos del nazismo chileno, el comunismo soviético estaba controlado totalmente por el judaísmo. "Se puede observar claramente que el comunismo es simplemente el producto de la corrupción y el judaísmo internacional" (Sznajder, 1993, pp. 280)

Por su lado, James Parkes señala que en América Latina los judíos se asentaron en las cuatro repúblicas en las cuales estaban interesados los nazis: Argentina, Brasil Uruguay y Chile, donde “(...) el antisemitismo era, y es todavía, una de las armas que los nazis podían usar con eficacia, sobre todo porque los judíos forman casi exclusivamente una población urbana y en su mayor parte viven en las capitales." (Parkes, 1965, p.181) 
En algún momento durante esos turbulentos años, apareció un grupo autodenominado "Asociación de Amigos de Alemania", cuyos directores eran algunos influyentes altos Oficiales del Ejército: Arturo Ahumada, Francisco Javier Díaz y Carlos Vergara Montero. Todos ellos fueron confesos admiradores de Hitler, a quien veían, paradojalmente, como garantía de estabilidad para el mundo; y profundos detractores de EE.UU. No obstante, no se tiene conocimiento de que hayan realizado actividades antisemitas, sino que más bien se trató de un organismo de fachada, para distribuir propaganda; y de presión, para mantener las relaciones con las potencias del Eje.

Al finalizar la presente revisión, no cabe duda que uno de los principales impulsores del antisemitismo en Chile ha sido Miguel Serrano Fernández, cuya trayectoria ha sido suficientemente tratada durante el diplomado, razón por la cual no se profundizará en ello.

\section{Conclusiones}

Uno de los factores más importantes que guía los principios generales por los cuales las personas unen sus intereses, es la necesidad de adaptación social, la presión por estar de acuerdo con las opiniones de aquellos con los que mantiene contacto con mayor frecuencia: cónyuge, familiares, compañeros de trabajo y vecinos.

Es así como los intereses de un individuo reflejan las diversas identidades que asume -partidista, racial, nacional, y así sucesivamente- reflejando, a su vez, las comunidades de las cuales es miembro. La importancia relativa asignada a cada una de estas identificaciones varía, individuo por individuo, en respuesta a una serie de factores sociales y psicológicos, algunas de ellas muy sutiles.

Un segundo factor determinante, es el efecto de los medios de comunicación ya que proporcionan pistas sobre lo que es aceptable o deseable en la cultura nacional y mundial de la época en particular en que se vive. 
Es allí donde aparece como sumamente útil el rol de la ideología, ya que una de sus principales funciones es proporcionar una guía útil para la opinión y la acción en general, sin la necesidad de llegar a estar muy familiarizados con los detalles de cada tema sobre el cual se debe adoptar una posición.

Como ha quedado de manifiesto de las páginas precedentes, todo ello estuvo presente al momento de promover el antisemitismo en su identificación como ideología. En especial durante la Alemania nazi, se trataba de estar de acuerdo con los que uno conocía, con la masa y, en última instancia, con lo que decía la propaganda estatal. En ello fue fundamental la labor del Ministerio de Educación Popular y Propaganda, creado por Adolf Hitler a su llegada al poder en 1933, con Josef Goebbels a la cabeza, y sus tres pilares básicos: anticomunismo, anticapitalismo y antisemitismo.

En ese orden, está ampliamente aceptado que el control ideológico se puede utilizar para mantener la estabilidad y montar la legitimidad. Esto se refleja, por ejemplo, en la "radical" visión del poder, que pone de relieve la capacidad de manipular las necesidades humanas. Los ejemplos más claros de manipulación ideológica se encuentran en los regímenes totalitarios que propagan una "ideología oficial" y suprimen, sin contemplaciones, todos los credos, doctrinas y creencias rivales. Los medios por los cuales esto se logra también son claros: la educación se reduce a un proceso de adoctrinamiento ideológico, los medios de comunicación se convierten en una máquina de propaganda, las creencias "poco fiables" son estrictamente censuradas y la oposición política es brutalmente erradicada. Fue de esta manera que el nacionalsocialismo se convirtió en una religión de Estado en la Alemania nazi, al igual que el marxismo-leninismo en la ex Unión Soviética.

La misma Hannah Arendt escribió:

"Muchos todavía consideran como un accidente el hecho de que la ideología nazi se centrara en torno al antisemitismo y la política nazi, consecuente e intransigentemente, se orientara hacia la persecución y finalmente al exterminio de los judíos. Sólo el horror de la catástrofe final y, todavía más, la pérdida de sus hogares y el desraizamiento de los supervivientes, convirtió a la «cuestión judía» en algo prominente en nuestra vida política cotidiana" (Arendt, 1973, p.28)

Es sabido que en determinados períodos los judíos fueron excluidos, cada vez más, de los beneficios de la sociedad en general y de la protección del Estado. Y en ninguna otra parte esto fue más evidente que 
en la Inquisición española, que constituye uno de los peores episodios de persecución organizada contra los judíos antes del siglo XX. Si bien el número de víctimas no se sabe a ciencia cierta, es un hecho histórico que miles de judíos fueron asesinados o exiliados como consecuencia de las crueldades de la Inquisición.

En directa relación con ello, expresiones como "el problema judío" de González von Marées en Chile, grafican exactamente la esencia de la intolerancia racial y de la negación de los derechos civiles y políticos, que en el escenario europeo quedó encasillada bajo la fórmula de "la cuestión judía", seguida de la infame solución final. A lo largo de la historia, en algunos casos, la concesión de derechos políticos estuvo asociada a la conversión o a algún otro tipo de purificación moral que fomentara el reconocimiento como ser humano y, al mismo tiempo, la eliminación de los aspectos menos socialmente deseables del Judaísmo.

James Parkes, autor ya citado, manifiesta, corroborando algunas afirmaciones efectuadas en párrafos previos, que:

"El antisemitismo es un producto secundario de los vastos electorados creados por la democracia del siglo XIX. La malignidad y el odio ya existían, es cierto, pero se manifestaban en forma diferente. EI antisemitismo del siglo XIX confiaba para su eficacia en la tendencia humana a hacer recaer las culpas en una víctima propiciatoria, a preferir los atajos del prejuicio del grupo al arduo camino de la comprensión" (Parkes, 1965, p. 13)

Igualmente decidor es cuando Arendt escribe que:

"Una diferencia fundamental entre las dictaduras modernas y todas las tiranías del pasado es la de que en las primeras el terror ya no es empleado como medio de exterminar y atemorizar a los oponentes, sino como instrumento para dominar masas de personas que son perfectamente obedientes. El terror, como hoy lo conocemos, ataca sin provocación previa, y sus víctimas son inocentes incluso desde el punto de vista del perseguidor. Este fue el caso en la Alemania nazi cuando se desencadenó el terror contra los judíos, es decir, contra personas con ciertas características comunes que eran independientes de su conducta específica" (Arendt, 1973, p.30)

Hoy en día, con el Holocausto como un recuerdo siempre presente, se ha producido un conocimiento básico de la injusticia cometida contra los judíos en todo el mundo, lo que ha contribuido a mitigar, en 
parte, las tendencias antisemitas. Sin embargo, el prejuicio religioso continúa siendo un problema, incluso en las sociedades más tolerantes y liberales, y nos recuerda la importancia de permanecer atentos ante la potencial reaparición de actitudes y prácticas antisemitas. La libertad de culto es tan significativa como siempre lo ha sido, y la necesidad de fomentar la tolerancia resulta vital para la promoción de la civilización. 


\section{NOTAS}

${ }^{1}$ Garrett Ward Sheldon, Enciclopedia de Pensamiento Político, Nueva York: Facts on File, 2001, p.154

${ }^{2}$ Para estudiar este punto recomiendo: Daniel J. Levinson, Capítulo III, El Estudio de la Ideología Antisemítica, en Estudios sobre el Prejuicio, Max Horkheimer y Samuel H. Flowerman editores, auspiciado por The American Jewish Committee, Social Studies Series: Publication N ${ }^{\circ}$ III.

${ }^{3}$ Stanley Payne, Historia del Fascismo, 1914 - 1945, Nueva York: Routledge, 1995, pp. 30 - 31.

${ }^{4}$ Es de hacer notar que Stewart estaba casado con Eva Wagner, la hija menor de Richard Wagner.

${ }^{5}$ Peter Pulzer, The Rise of Political Anti-Semitism in Germany and Austria, Nueva York, 1964, pp. 112 113. Citado en Richard Evans, La llegada del Tercer Reich. El ascenso de los nazis al poder, Barcelona: Península, 2003, p. 53

${ }^{6}$ Payne, op. cit. p. 341.

${ }^{7}$ Carlos Keller Rueff (Concepción, 3 de enero de 1897-28 de febrero de 1974). Cursó sus estudios secundarios en Leipzig (Alemania) y en sus sus estudios universitarios fue discípulo de Oswald Spengler. Ejerció como Vicepresidente del Movimiento Nacional-Socialista de Chile hasta 1941.

${ }^{8}$ De Spengler habían aprendido a distinguir entre cultura y civilización, asociando alma y el espíritu con la primera, y considerando a la última como el estado más externo y artificial que la raza humana podía alcanzar. 


\section{Bibliografía}

ARENDT, Hannah. Orígenes del Totalitarismo. México, Taurus, 1973.

BELLER, Steven. Antisemitismo: Una Breve Introducción. New York, Oxford University Press, 2007.

EAGLETON, Terry. Ideología. Una Introducción. Londres, Verso, 1991.

HEYWOOD, Andrew. Political Theory. Saint Martin`s Press, New York, 1999.

LEVINSON, Daniel J. Capítulo III, "El Estudio de la Ideología Antisemítica”, EN: HORKHEIMER, Max y

FLOWERMAN, Samuel H. (Eds.) Estudios sobre el Prejuicio, Social Studies Series: Publication N III.

MIRANDA CARRINGTON, Sergio "Homenaje a los veinte años del Nazismo chileno", 5 de Septiembre 1938, 5 de Septiembre de 1958 (Santiago 1958). Citado en "Nazismo en Chile: un particular tipo de fascismo en Sud América".

NEEDLER, Martin C., Identidad, Interés e Idología. Una Introducción a la Política. Westport, Connecticut, Praeger, 1996.

PARKES, James. Antisemitismo. Buenos Aires, Paidós, 1965.

PAYNE, Stanley. Historia del Fascismo, 1914 - 1945. Nueva York, Routledge, 1995.

PULZER, Peter. The Rise of Political Anti-Semitism in Germany and Austria. Nueva York, 1964, pp. 112 -

113. Citado en Richard Evans, La llegada del Tercer Reich. El ascenso de los nazis al poder, Barcelona: Península, 2003.

SHELDON, Garret Ward. Enciclopedia de Pensamiento Político. Nueva York, Facts on File, 2001.

SMITH, R. Fontana History of the Human Sciences. pp. 556 - 557. Citado en Peter Watson, Ideas. Historia Intelectual de la Humanidad.

SZNAJDER, Mario. Un caso de nazismo no-europeo: el Nacional Socialismo chileno de los años 30. Journal of Contemporary History, XXVIII (2), Apr., 1993.

WIDOW, Juan Antonio. El hombre animal político. Santiago, Universitaria, 1984. 